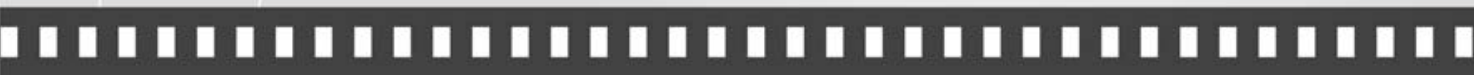
Vida e obra de Charles Sanders Peirce e as bases para 0 \begin{tabular}{l} 
estudo da linguagem fotográfica \\
\hline
\end{tabular}

Jorge Barros Pires 


\title{
Vida e obra de Charles Sanders Peirce e as bases para 0 estudo da linguagem fotográfica
}

Life and works of Charles Sanders Peirce and the bases for the study of the photographic language

\author{
Jorge Barros Pires*
}

\begin{abstract}
Resumo: Este artigo apresenta a vida e a obra de Charles Sanders Peirce com o objetivo de estimular o interesse por seu estudo $e$ facilitar a compreensão de trabalhos que vêm sendo publicados nesta revista. Pelas perspectivas que oferece aos estudos da linguagem fotográfica e pela contribuição dessa importante teoria da significação para as abordagens mais amplas da visualidade, aspectos fundamentais são aqui discutidos. Como resultado, constrói-se um esclarecimento da terminologia para permitir maior clareza sobre seu poder de gerar recursos de descrição e análise.
\end{abstract}

Palavras-chave: semiótica; semiótica peirceana; vida e obra de Peirce; fotografia; visualidade.

\begin{abstract}
This article is about the life and works of Charles Sanders Peirce with the purpose of fostering the interest in their study and improving comprehension of other articles being published in this revue. For the perspectives it provides to the studies of photographic language and for the contribution of this important theory of signification to the wide field of visual communication, key issues are here discussed. As a result, a clarification of terminology to enhance clearness on its power of generating resources for description and analysis is provided.
\end{abstract}

Key-words: semiotics; peircean semiotics; Peirce's life and works; photography; visuality.

* Pesquisador do projeto Cognitus/Petrobrás. Mestre em Filosofia pela Unesp e doutorando em Engenharia pela UFRJ. 


\section{Introdução}

Sempre presente nos estudos de todas as formas de linguagem, a filosofia de Charles Sanders Peirce, compõe um vasto universo de conceitos que, exatamente pela amplitude que alcança, suscita uma visão mais atenta, sobretudo do sentido de sua terminologia. Este artigo visa enriquecer as perspectivas já conhecidas em estudos de fotografia ao detalhar, com mais elementos, a obra do filósofo e buscar ampliar a compreensão dos conceitos que costumam ser transportados para as análises fotográficas em particular, e da visualidade de um modo geral.

O interesse desta abordagem é apontar a compreensão que se obtém das categorias universais presentes nos fenômenos quando se compreende a classificação de ciências do autor. Com efeito, é a partir do momento que se torna clara essa classificação, que se consegue desvendar a profundidade e o alcance dos conceitos daquelas categorias. Este procedimento, dentre uma infinidade de outras condutas com o emprego da teoria, adquire a especial relevância de orientar estudos da imagem que utilizam abordagens de semiótica peirceana. Por essa importância, um estudo específico se justifica. Aqui se pretende discorrer a respeito da trajetória do filósofo e evidenciar como foi evoluindo o corpo teórico que desenvolveu.

\section{Filósofo-cientista ou cientista-filósofo}

Peirce é considerado um dos principais nomes da filosofia americana. Autor de textos de extrema originalidade e de volume notável, produziu uma obra cujo escopo e abrangência só é comparado a Leibniz. (JOLLEY, 1995). Estudioso disciplinado, Peirce pesquisou cuidadosamente os métodos de investigação, dedicando especial atenção às ciências exatas. Conviveu com as mais ilustres mentes das ciências físicas. (CP 1.3)ํㅗ․

\footnotetext{
${ }^{1}$ Referir-nos-emos aos textos de Charles S. Peirce contidos nos Collected Papers pelas iniciais CP seguidas do número do volume e do parágrafo. A mesma convenção vale para suas outras obras: NEM para The New Elements of Mathematics; W para Writings of C. S. Peirce.
} 
Embora tenha sido um filósofo, foi primeiramente um cientista. Graduou-se em química pela Harvard University em 1859 e trabalhou regularmente para a U. S. Coast and Geodedic Survey de 1859 a 1891. Quando em 1857 participou de meetings da International Geodetical Association tornou-se o primeiro cidadão americano a representar os Estados Unidos em um meeting internacional de Ciências Físicas. No mesmo evento, Peirce estabeleceu para si mesmo e para a Coast and Geodetic Survey respeito internacional por apontar um erro no método europeu para realizar observações da gravidade. (NOAA, 2008).

Cientista e autor versátil, não se limitou aos trabalhos da Coast and Geodetic Survey, tendo incursionado por diversas áreas de pesquisa. Entre elas estão estudos em astronomia² ${ }^{2}$ química, biologia, espectrologia, óptica, filologia, arquitetura, lingüística e história. Contribuiu consideravelmente para a psicologia, tornando-se um dos primeiros psicólogos experimentais da América. (PEIRCE, 1972). Exerceu grande influência sobre a formulação teórica do pragmatismo e da lógica clássica. Efetuou ótimos trabalhos sobre a lógica dos relativos, a teoria dos signos, probabilidade e indução e lógica matemática³. (SANTAELLA, 1995).

Tal diversidade de estudos possuía um “fio condutor” em comum: a lógica, paixão que o acompanhou por toda sua vida ${ }^{4}$. Estudou profundamente lógica, em especial o pensamento medieval, não se furtando ao grego, inglês, alemão e francês. (CP 1.3). Sua primeira imersão nesse tema foi extremamente precoce: aos 12 anos de idade estudou profundamente o livro Elements of Logic de Richard Whately (cf. a reimpressão desse livro em Whately, 2005). Por volta dos 16 anos de idade, por mais de três anos, empreendeu incansáveis estudos sobre a

\footnotetext{
${ }^{2}$ Seus relatórios de trabalho a respeito de fotometria são impressionantes (cf. W, 382-493).

${ }^{3}$ O livro Studies in Logic (PEIRCE, 1883), que apresenta uma coleção de ensaios realizados por Peirce e seus alunos da Johns Hopkins University, é uma boa referência de seus trabalhos em lógica matemática.

${ }^{4}$ Quando indicado em 1867 para ingressar na Academia Americana de Ciências e Artes, apresentou somente cinco estudos, todos em lógica. Foi indicado para a Academia Nacional de Ciências durante cinco anos consecutivos; em todos apresentou somente trabalhos em lógica. Finalmente quando aceito como membro, em 1877, agradeceu a implícita aceitação da lógica como ciência, pois em sua época a mesma não possuía tal reconhecimento. (SANTAELLA, 1995).
} 
Crítica da Razão Pura de Kant, chegando a sabê-la de cor. (Cf. CP 1.4). Isso acarretou uma profunda admiração por esse autor. Uma admiração que não se resumiu à idolatria, mas sim a uma crítica séria e obstinada.

Ele considerava a filosofia de tradição alemã uma grande fonte de sugestões filosóficas, contrapondo-se à de tradição inglesa que considerava destituída de bases, porém, dona de "métodos mais seguros e mais acurada lógica”. Percebeu em Duns Scotus, dadas as devidas reformulações em favor de uma cultura moderna e o controle do criticismo do nominalista, uma lógica e uma metafísica que poderiam ajudar na construção de uma filosofia que melhor se harmonizasse às ciências físicas. (CP 1.6). Segundo suas próprias palavras:

Minha filosofia pode ser descrita como a tentativa que um físico desenvolve no sentido de fazer conjetura acerca da constituição do universo, utilizando métodos científicos e recorrendo à ajuda de tudo quanto foi feito por filósofos anteriores. Apoiarei minhas proposições nos argumentos que estejam a meu dispor. De prova demonstrativa não cabe cogitar. As demonstrações dos metafísicos não passam de aparências. O mais que se pode conseguir é fazer surgir uma hipótese não inteiramente despida de procedência, que se coloque na linha geral de desenvolvimento das idéias científicas e que seja suscetível de ver-se confirmada ou refutada por observadores futuros. (CP 1.7).

De fato, Peirce foi um filósofo-cientista ou cientista-filósofo. Foi um pensador que, possuindo o espírito do laboratório, conseguiu elaborar sua filosofia e todos os sub-ramos como disciplinas científicas. Em sua concepção, a filosofia é uma ciência porque ela tem que encontrar, nela mesma, seus próprios meios de observação, suas hipóteses e experimentos, segundo uma metodologia que lhe é específica. (SANTAELLA, 1992). Essa característica multi, inter e por vezes transdisciplinar que possuía, tornou muito difícil que ele fosse compreendido tanto por filósofos quanto por cientistas de sua época. (SANTAELLA, 1993).

Sua obra, considerando-a pioneira em diversos de seus aspectos, ainda hoje é fruto de mal-entendidos. A interpretação de sua teoria 
costuma ser encarada de forma parcial e reducionista. A falta de edições mais completas de seus manuscritos é um dos motivos desse problema. A dificuldade de se acessarem seus textos, por vezes acaba gerando análises parciais de suas idéias. Isso é um grande problema, porque a Filosofia de Peirce é um sistema que foi construído de modo que suas partes são co-implicadas. A relação entre os subsistemas, ou subramos, é efetivada numa relação hierárquica de interdependências. A seu ver, a própria filosofia possui esse tipo de relação com as outras ciências. Quaisquer análises superficiais, que não levem em conta essas inter-relações, podem conduzir a enganos conceituais importantes.

Portanto, no sentido de evitar qualquer tipo de mal-entendido, convém uma pequena introdução à classificação das ciências de Peirce, na qual se ressalte a posição e o papel da fenomenologia no interior da filosofia, ao mesmo tempo em que se examinem suas relações com a semiótica.

\section{A classificação das ciências}

O século XIX deixou a noção de que a ciência poderia ser resumida a um conjunto coerente e sistematizado de conhecimentos. Peirce coloca-se abertamente contra esse tipo de entendimento, bem como de qualquer outra definição abstrata. A idéia de ciência adotada por ele é muito mais que qualquer acúmulo de conhecimento ou conhecimento organizado: é um modo de viver de alguns homens (SANTAELLA, 2001), uma vida dedicada à investigação da verdade, "não devoção à verdade como cada um a vê pessoalmente, pois isso não é, de modo algum, devoção à verdade - mas devoção à verdade que não se é ainda capaz de ver, mas se está lutando por obter” (FISCH, 1982), fruto de forte impulso para se penetrar na razão das coisas.

Ciência para Peirce é um atributo que está longe de ser uma exclusividade do universo acadêmico, com suas elaborações teóricas e 
altamente abstratas. Ciência é um modo de vida dedicado à busca da verdade, posta em efeito por uma inteligência capaz de aprender com base na experiência. (SILVEIRA, 2000). Não importa quão imperfeito possa, ou quão sujeito ao erro, possa ser o conhecimento, a partir do momento em que essa inteligência busca aprender e compara suas idéias com os resultados da experiência, a fim de corrigi-las, aquilo que o ocupa é a ciência. (CP 1.44, 7.54-55).

Por isso não é o conhecimento, mas o amor pelo saber, que caracteriza o homem científico. (CP 1.44). É na generalização do desejo de aprender que são criadas classes cada vez mais vastas na ciência, e é na busca contínua pelo aprendizado que tal desejo vai se especificando, do mesmo modo que as ciências se especificam. Por meio dessa devoção, cada um deles adquire prática em fazer algum tipo particular de observação e experimentos. (CP 1.236).

Homens que são equipados e treinados para um tipo de observação são capazes de entender uns aos outros, eles vivem no mesmo mundo. Aqueles que possuem outro tipo de treinamento e equipamentos são estrangeiros para eles. (CP 1.99). Mas, para Peirce, nos próximos anos, os mais altos lugares na ciência serão daqueles que tiverem sucesso em adaptar os métodos de uma ciência para a investigação em outra. (CP 7.66). A relação dinâmica entre diferentes ciências, umas atuando sobre as outras, irá estimular a solução de problemas que sozinhas não conseguiriam. (CP 7.52). Isso envolve o compromisso de que cada cientista esteja, como uma espécie de filósofo, ávido em aprender com outras áreas e refletindo o que foi aprendido em sua própria área, tentando que isso faça sentido em toda a árvore do conhecimento. (NUBIOLA, 2005).

Ou seja, os propósitos e métodos fundamentais de cada grupo de cientistas é que guiaram Peirce em sua divisão das ciências, sendo a modificação desses propósitos a responsável pelo surgimento de seus ramos e sub-ramos. (CP 1.238). Por outro lado, a classificação nos permite visualizar o papel e nível de abstração que cada uma delas possui, bem como as inter-relações e os meios com que uma ciência pode ajudar outras. (KENT, 1987). 
Ao construir a Classificação das Ciências (figura 1), Peirce tomou emprestado de Comte, a idéia de que cada ciência depende dos princípios que outras mais gerais a fornecem, excetuando-se a matemática que, sendo a mais geral e abstrata, tem suas formulações, fundamentalmente hipotéticas, independentes de qualquer outra. (CP 1.180, 1.244-245). Desse modo, ele tornou possível saber com quanto as ciências mais formais poderão auxiliar na fundamentação das menos formais. E da mesma forma, as ciências menos formais podem oferecer desafios, por meio de novos problemas e/ou de testes, para as teorias formalizadas. (KENT, 1987).

Para Peirce (CP 1.184 e 1.241), a filosofia é uma ciência que trata da verdade enquanto fruto de observações no universo da experiência comum. O tipo de filosofia que interessava a ele é aquela que usa os mais racionais métodos para descobrir o que ainda pode ser encontrado a respeito do universo da mente e da matéria, a partir das observações que toda pessoa pode fazer a qualquer momento de sua vida, não incluindo aqueles assuntos que são mais convenientemente estudados por ciências especiais, tal como a física, a psicologia, entre outras. (CP 1.126). Ao buscar aquilo o que é por todos compartilhado, Peirce manifesta uma irrestrita confiança no poder da razão e renuncia a qualquer tipo de privilégio em pronunciar a verdadeira realidade das coisas. (SILVEIRA, 2007).

Peirce dividiu a filosofia em três classes: fenomenologia; ciências normativas; e metafísica. (CP 1.186). A fenomenologia é a ciência que estuda os elementos universalmente presentes em todos os fenômenos, sejam eles reais ou não. É a ciência que se preocupa com as aparências ${ }^{5}$ no universo da experiência. (CP 1.190). As ciências normativas investigam as condutas de uma mente que aprende pela experiência. Ela é dividida em: a) estética, que visa os ideais últimos; b) ética, a teoria da conduta deliberada e autocontrolada; c) lógica ou semiótica, ciência voltada às condições gerais da conduta autocontrolada de uma mente que aprende com a experiência em busca de seu ideal último. Sendo todo o conhecimento formado a partir de signos, é o estudo das leis gerais do signo. (CP 1.191).

\footnotetext{
${ }^{5}$ Appearances, no sentido aparecer.
} 


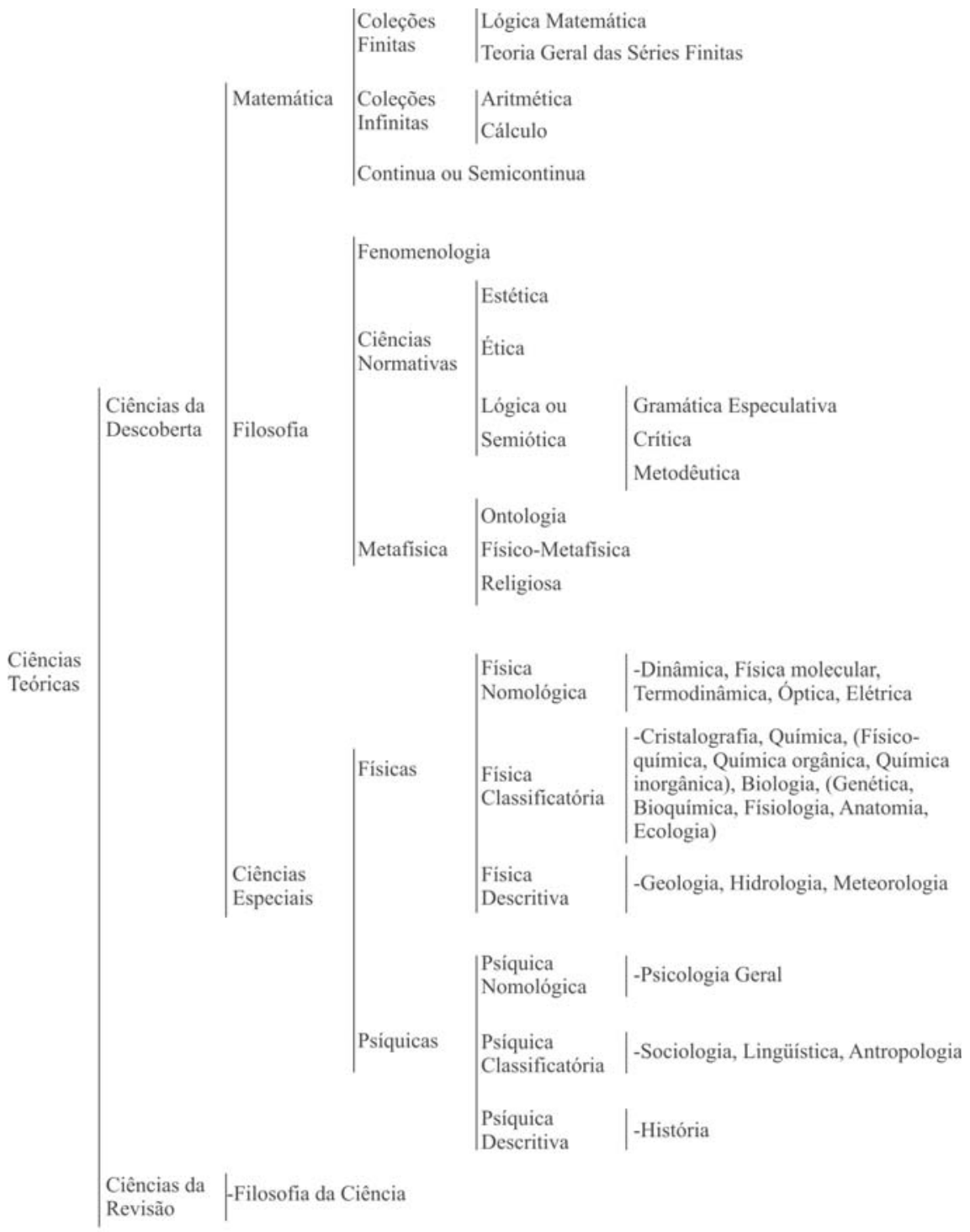

Ciências $\quad$-Arte, Telefonia, Ética (ciência da moralidade), Biblioteconomia, Navegação, Leis (Jurisprudência) Práticas 
A metafísica visa estudar a realidade do mundo, colocando-se a responder questões referentes à liberdade, tempo, espaço e sobre as leis da natureza e da matéria. (CP 1.192). Cada uma das ciências filosóficas possui um grau de generalidade diferente da outra. Cada uma delas busca explicar um determinado espectro do universo da experiência. Elas são inclusivas e complementares na compreensão do universo da experiência.

Este é um quadro classificatório, cuja base está apoiada numa concepção lógica, estabelecendo as relações e intermediações de uma ciência à outra na busca pelo admirável. Não cabe discutir de modo exaustivo todas as ciências existentes, isso nos desviaria do objetivo principal. Nosso objetivo nesta seção foi apenas indicar um caminho para que se pudesse visualizar a posição que a Filosofia de Peirce ocupa em relação às outras, bem como sugerir o meio pelo qual as ciências de um modo geral se interconectam. O próximo passo é detalhar um pouco mais a fenomenologia peirceana.

\section{Fenomenologia}

A fenomenologia se apresenta como a mais elementar entre as ciências filosóficas. Seu estudo se identifica com a experiência comum, estudando, esvaziadas ao máximo de qualquer preconceito, as características dos fenômenos. (CP 1.190, 1.284). Não se pretendendo uma ciência da realidade, a fenomenologia irá se dedicar a todo e qualquer fenômeno no universo da experiência. Mas o que Peirce tinha em mente ao falar de fenômenos? Peirce (CP 1.284) entendia fenômeno como o “total coletivo de tudo aquilo que está de qualquer modo presente na mente, sem qualquer consideração se isto corresponde a qualquer coisa real ou não”. Ou seja, o fenômeno é algo que a experiência força sobre nossa mente, seja ela a mais selvagem alucinação ou as conclusões das ciências. Percebamos que esse conceito é compatível com a idéia de fenômeno que apresentamos na introdução deste trabalho. Ou seja, 
fenômenos estão relacionados a processos que se impõem à mente. Sua correspondência com a realidade é irrelevante nesse momento. O que de fato importa são suas características fundamentais.

Em carta endereçada a Lady Welby (12/10/1904), Peirce, antes de tratar de sua classificação dos signos, expõe as três categorias universais presentes em todo e qualquer fenômeno, sendo elas: Primeiridade, Secundidade e Terceridade. (CP 8.328). Por Primeiridade entende-se aquilo que é o que é, sem referência a nada mais; Secundidade é aquilo que é em relação a um outro, mas não se referindo a um terceiro; e Terceiridade é aquilo que mantém uma relação triádica, ou seja, se coloca em relação mútua tanto a um segundo quanto a um terceiro. (CP 8.328). ${ }^{6}$

A Primeiridade se caracteriza pelas qualidades de sentimento. Uma consciência que está presente num ponto do tempo, sem partes ou referência a qualquer análise ou comparação, onde pensamento algum pode se inserir e nada pode ser isolado. (CP 1.306, 8.329). São aqueles fenômenos que se apresentam sem a interferência de nenhum outro. Não existe passado ou futuro, apenas o momento presente, novo e original. Uma consciência que rompe com o tempo, tornando-se mera possibilidade.

A idéia de primeiro é predominante na idéia de novidade, vida, liberdade. Livre é aquilo que não tem outro atrás de si determinando suas ações. (CP 1.302). As idéias típicas de primeiridade estão nas qualidades de sentimento ou meras aparências. [...] É simplesmente uma possibilidade positiva peculiar, independente de tudo o mais. (CP 8.329). Por um sentimento eu entendo um exemplo daquele tipo de consciência que não envolve qualquer análise, comparação ou qualquer processo que seja, nem consiste, no todo ou em parte, de qualquer ato pelo qual uma extensão de consciência é distinta de outra e que tem sua própria qualidade positiva, que consiste em nada além disto e que é de si mesma tudo o que ela é. (CP 1.306). Um sentimento é um estado, que assim é em sua totalidade, em todo momento de tempo e na medida em que ele dure. (CP 1.307).

\footnotetext{
${ }^{6}$ Suas categorias denominadas "cenopitagóricas” se mostram irredutíveis umas às outras. As demonstrações desta irredutibilidade podem ser encontradas em: CP 5.82-92, 7.537.
} 
Com essas palavras, Peirce elimina da primeira categoria fenomenológica qualquer traço de compulsão bruta ou de racionalidade mediativa. Nessa categoria, o estado pelo qual a mente experimenta o novo, a liberdade, a espontaneidade não depende de qualquer tipo de força ou imposição, ainda que em sua vida ordinária ele só encontre essa talidade (suchness) ${ }^{7}$ em meio a uma rede de determinações ${ }^{8}$. (SILVEIRA, 2002). Cremos que não há necessidade alguma de se pensar que essa qualidade monádica apareça apenas em algumas instâncias privilegiadas. Pelo contrário, o sensível é primeiro e permeia todas as esferas do cosmos.

Basta voltarmos nossos olhos à natureza para que nos deparemos com uma incrível diversidade de formas, cores, odores e sabores emergindo com o frescor da novidade, todas elas frutos da espontaneidade do universo. Nas palavras de Peirce, "vá sob o azul do firmamento e olhe o que está presente tal como surge aos olhos do artista (CP 5.44)". O que se verá é a liberdade brotando, uma consciência imediata, espontânea e de caráter incondicionado.

A Secundidade é a categoria que tem no seu modo de ser o fato atual, objetivo. Está vinculada às relações que mantém dentro do universo da experiência, sendo estas relações puro fato bruto. Uma experiência privada de objetivo, é ação e reação, esforço e resistência. (CP 1.24, 8.330). Para Peirce, a consciência de um certo sentimento sendo rompido por um outro é o que se pode chamar de experiência. Um acontecimento que se força contra o pensamento, levando a uma mudança na consciência. Este estado de esforço bruto se coloca como um outro que se impõe na relação com o primeiro. Binaridade que faz a ligação entre um primeiro e um segundo sem qualquer mediação. (CP 8.330). Um confronto que traz a uma idéia de individualidade, do isto e não aquilo.

Assim também, se apresenta o fato passado, fenômeno sobre o qual não se tem qualquer poder de persuasão. Este consiste num aglomerado de fatos, agindo sobre a mente na tentativa de se perpetuar. (CP 5.459, 6.140). É algo que determina seu existir com vistas no

\footnotetext{
${ }^{7}$ Sucheness (Talidade) é o termo usado por Peirce para designar aquele aspecto de toda qualidade de sentimento que fará do fenômeno ser absolutamente primeiro. (IBRI, 1992).

${ }^{8}$ Cabe lembrar que não estamos nos referindo, de forma alguma, ao determinismo mecanicista.
} 
futuro. "Se você se queixar ao passado que ele está errado e não é razoável, ele se rirá. Sua força é bruta (CP 2.84)”. A experiência é força bruta que se impõe sobre o pensamento. O passado age sobre nós da mesma forma que um objeto o faz são fatos que se forçam sobre a mente, levando-a a mudanças de conduta. (CP 8.330, 5.459 e 6.140). Segundo Peirce:

Estamos continuamente colidindo com o fato duro. Esperávamos uma coisa ou passivamente tomávamo-las por admissível e tínhamos sua imagem em nossas mente, mas a experiência força essa idéia ao chão e nos compele a pensar muito diferentemente. (CP 1.324).

A Terceiridade é a categoria que se caracteriza pela mediação, um terceiro relacionando o ato causal e o seu efeito. Age com força de lei, mediando e possibilitando as relações entre dois elementos (CP 1.328), é um “estar entre” que encontra na representação sua plenitude. (CP 5.104). É uma forma de consciência mediata que, diferentemente da primeira categoria, não pode ser reduzido a um ponto no tempo; bem como não se reduz a uma ocorrência bruta, característica da segunda categoria. É a consciência de um processo, que não pode ser imediato; é cognição, um fenômeno que envolve um determinado tempo. (CP 1.381). A cognição se vincula ao futuro como sua formadora. Através da generalização do fato bruto, ela proporciona a representação das circunstâncias em que poderão vir a ser. Irá procurar estabelecer as leis gerais que determinarão a conduta auto-controlada para sua efetivação.

Parece, então, que as verdadeiras categorias da consciência são: primeiro, sentimento, a consciência que pode ser incluída com um instante de tempo, consciência passiva de qualidade, sem reconhecimento ou análise; em segundo lugar, consciência de interrupção no campo da consciência, sentido de resistência, de um fato externo, de alguma outra coisa; em terceiro lugar, consciência sintética, ligação com o tempo, sentido de aprendizagem, pensamento. (CP 1.377). 


\section{Considerações finais}

A fenomenologia, tal como foi exposta, fica confinada às aparências do fenômeno. Ela apenas classifica aquilo que está diante da mente, nada asseverando a respeito da conduta que será assumida diante dele. (IBRI, 1992). Serão as ciências normativas que nos levarão a compreender o que, em tudo que aparece, motiva, em última instância, a conduta.

\section{Referências}

FISCH, Max. Peirce's place in American life. Historia Mathematica, London, v.9, n.3, p.265-289, aug. 1982.

IBRI, Ivo Assad. Kósmos Noetós: a arquitetura metafísica de Charles S. Peirce. São Paulo: Perspectiva/Hólon, 1992.

JOLLEY, Nicholas. The Cambridge Companion to Leibniz. Cambridge: Cambridge University Press, 1995.

KENT, Beverley. Charles S. Peirce: logic and the classification of the sciences. Kingston and Montreal: McGill-Queen's University Press, 1987.

NATIONAL OCEANIC AND ATMOSPHERIC ADMINISTRATION.- NOAA. Giants of Science. Disponível em: http://www.history.noaa.gov/giants/peirce.html. Acesso em: 15 fev. 2008.

NUBIOLA, Jaime. The classification of the sciences and crossdisciplinarity. Transactions of the Charles S. Peirce Society, Indianapolis, v.41, n.2, p.271-282, 2005. 
PEIRCE, Charles Sanders. Semiótica e filosofia. São Paulo: Cultrix, 1972.

Studies in Logic, by Members of the Johns Hopkins

University (1883). Amsterdam: John Benjamins Pub co, 1984.

.The Collected Papers of Charles Sanders Peirce. In: HARTSHORNE, Charles; WEISS, Paul; BURKS, Arthur (Org.). Cambridge: Harvard University Press, 1958, v.8.

.Writings of Charles S. Peirce: a chronological edition.

FISH, Max et al. (Ed.) Bloomington: Indiana University Press, 1994, $5 \mathrm{v}$.

SANTAELLA, Lúcia. A assinatura das coisas: Peirce e a literatura. Rio de Janeiro: Imago, 1992.

Apercepção: uma teoria semiótica. São Paulo:

Experimento, 1993.

A teoria geral dos signos: semiose e autogeração.

São Paulo: Ática, 1995.

. Comunicação e pesquisa: projetos para mestrado e doutorado. São Paulo: Hacker, 2001.

SILVEIRA, Lauro Frederico Barbosa da. Acaso, existência e lei em um universo em evolução. Cognitio: Revista de Filosofia, São Paulo, v.1, p.127-137, 2000.

. Curso de semiótica geral. São Paulo: Quartier

Latin, 2007. 
Os primeiros passos rumo à verdade. Cognitio: Revista

de Filosofia, São Paulo, v.3, p.107-114, 2002.

WHATELY, Richard. Elements of logic. Boston: Adamant Media Corporation, 2005. 